\title{
Lecturers' Industrial Attachment Programme to Increase Lecturers' Soft Skill and Technological Competencies for Global Stability and Security
}

\author{
Mohamad Fadzil Basir Ahmad \\ Innovation and Research Unit, Seberang Perai Polytechnic \\ 13500 Bukit Mertajam, Penang. Malaysia \\ Tel: 60-4-538-3322Ｅ-mail: fadzil@psp.edu.my \\ Kamarul Ariffin Abd Rashid \\ Training and Continuous Studies Unit, Seberang Perai Polytechnic \\ 13500 Bukit Mertajam, Penang. Malaysia \\ Tel: 60-4-538-3322 E-mail: kariffin@psp.edu.my
}

\begin{abstract}
Knowledge is Power for Global Stability and Security. As part of the Polytechnic's Transformation Plan, lecturers are encouraged to undergo industrial attachment in the related industries to broaden their outlook, experience and keep-up with the latest development in technology. By undergoing the two months attachment stint with the industries, they have the opportunity to experience the real-life working environment especially for those who don't have the experience. As the result, lecturers will be able to gather knowledge and up-to-date skill which can be shared with their colleagues and students in order to benefit and enrich their learning experiences. Based on the interview held, it proves that the LIA programme helps to boost the lecturers' competency in their area of specialisation in both pedagogical and technical aspect.
\end{abstract}

Keywords: Attachment, Knowledge, Lecturer and LIA programmes

\section{Introduction}

In response to the rapid changes in industrial and economic development posed by globalisation, the technical education system too needs to be reviewed to keep up with the changes and continue to equip students with relevant skills to prepare them for the global competitive landscape.To produce students who are capable and suit with the changes, the technical skill alone is not adequate. Students must also be equipped with soft skills, appropriate work attitude and professionalism so that they could become effective and productive contributor to their organisation. In order to achieve this goal, the lecturers must be competent not only in the pedagogical aspect for effective delivery of modules or in the technical aspect based on the discipline or area to be taught but also the need of industrial experience for practical skills upgrading specific to industry practice and procedures (ILO/CINTERFOR, 2001). Pedagogical competencies and technical competencies can be improved through experience and in-service courses and training in the form of conference, seminar, workshop, short courses or symposium. Meanwhile the only way to gain industrial experience is through industrial attachment programme. Through the real working exposure in industries or related organisation, lecturers could learn the latest technology and at the same time gain knowledge in other areas such as management, innovation, quality control circle, marketing, sales strategy, best practice and interpersonal skill in industries. This new experiences could be translated into teaching strategies that surely will benefit the students. In conclusion, the work based learning is important to provide opportunity to lecturers to gain structured training and learning process at actual work place (Mitchell, Henry \& Young, 2001).

\section{The LIA Objective}

Lecturers of the polytechnic are responsible in the implementation of the teaching and learning process in their respective disciplines. Other main responsibilities are assessing the students, planning curriculum, develop and managing the course. The lecturers are also needed to assist in organising events, competitions and activities, exhibitions, industrial training visit and establishing closer ties with industry and relevant organisations. They are also required to perform research and present their research papers at the national and international level. Therefore, lecturers must be fluent in both the Bahasa Melayu as the national language and English which will 
further allow them to compete globally. Furthermore, they should also possess strong administrative and interpersonal skills.

The main objective of LIA is to broaden lecturers' knowledge and experience that would help them in enhancing personal and professional competencies so that their responsibilities as mentioned above can be carried out more efficiently thus achieving the organisation stability and security.

\section{The LIA Process}

Since the lecturers' attachment programme was started, a total of 449 lecturers have been attached with 381 companies. In 2009 alone, 61 lecturers underwent attachment in 59 companies. (Imran I, 2008)

The industrial attachment process is divided into three stages namely before, during and after. Before the attachment, the lecturers need to find the suitable organisation related to their respective fields. It is strongly recommended that the LIA programme is completed at any of the private sector organisation. Priority will be given to the multinational companies such as Intel, Motorola etc. and companies that do provide structured training programme or at least tailored training programme. This is the initial task that requires the lecturer's effort to communicate and coordinate with the particular organisation.

The second stage is during the attachment. The duration allocated for the LIA programme is two months. During the two months period, lecturers are expected to be exposed to various work areas such as technical, maintenance, operation, management etc. The attachment task schedule depends to the organisation's convenience. Throughout the attachment, lecturers will be guided by the supervisors assigned by the organisation. The officers from the Training and Continuing Education Unit which is in-charge of the LIA programme will visit the lecturers to assess and monitor their progress.

The final stage is after the attachment. After completing the attachment, the lecturers need to prepare a report outlining their achievement during the attachment and they also need to present their experience and share the knowledge gained with their colleagues through seminar, short courses or colloquium.

\section{What do the lecturers say?}

Outcome of the structured interview held among the randomly selected lecturers from various department who have attended the LIA programme are as follows:

\section{Department of Electrical Engineering Lecturer - Telecommunication Industry}

I'm teaching data communication module. After attending industrial attachment program, I could elaborate theoretical aspects more effectively and efficiently and relate them with the latest development in the telecommunication industry to my students. Apart from seeing the highly advanced technology used in the company and the types of equipment used in the industry, the notes and hand-outs provided during the program helps me a lot in my teaching and learning processes. Learning from experience is the best and the experience gained is invaluable. I can share with the students the criteria that they must possess for the company to employ them. Besides that, the close relationship nurtured with the company might benefit the students in some ways such as creating job opportunities for polytechnic students.

\section{Commerce Department Lecturer - Insurance Company}

Planning processes and programs implementation obtained during the internship stint could well be adapted in the programs or courses that will be organised by the polytechnic. In terms of the communication skill, the interactions with the students during lecture sessions and with the colleagues are greatly improved.

By acquiring additional knowledge throughout the attachment program, the teaching and learning processes are getting more effective. This is because, any explanation and discussion regarding certain topic will be clarified and strengthen by giving detailed and latest examples. Apart from that, I am able to share the latest information related to the insurance industry in Malaysia with my students and at the same time encourage them to join this industry as their future career once they graduated from the polytechnic.

\section{Department of Electrical Engineering Lecturer - Electronic Industry}

After completing my attachment program, I managed to acquire some basic knowledge regarding the microcontroller. I am capable of giving some exposure and understanding particularly to the full-time and part-time students for the Project Module in Electronic Engineering Course.

The valuable knowledge obtained are utilised in assisting the students to develop their project by using microcontroller technology especially for the part-time students. The ideas and concepts exposed to them will be applied to diversify the output of their projects. 


\section{Commerce Department Lecturer - Shipping Industry}

The self confidence in voicing opinions, ideas and suggestions is greatly improved. The effective and efficient working culture is applied and adapted in the daily tasks. The communication skill is drastically improved with all groups of workers from lower level up to the top level of management.

During the teaching session, I indirectly inculcate some noble values in producing well balanced students in both spiritual and academic achievement, sharing of knowledge and expose the students with all the important tips of how to deal with the challenges of the outside world particularly if they want to be part of the private sector work force.

\section{Department of Information Technology Lecturer - Airline industry}

My three months experience in a giant corporation such as Airline Company cannot be used as a gauge to measure my competency level. This is because the company is a profit oriented corporation. However, I gained invaluable experience and knowledge in various aspects such as security, culture of work and integrity which contributed significantly to my routine works involving teaching and learning processes. Knowledge and information sharing with my colleagues and students are greatly enhanced. My level of confidence in dealing with my job is also improved.

\section{Challenges faced during the LIA}

Behind the successful stories there are also some challenges faced by the participants of the LIA programme such as their proficiency of English language especially in the multinational companies, the work culture of private sectors that are contrary from the government agencies, being an engineer and the ability to solve technical problem with minimum supervision. However the lecturers managed to overcome the challenges faced after a period of time.

\section{Conclusion}

From the finding of the interview, we can conclude that the objective of LIA programme is achieved. The attachment has become the learning process which exposed the lecturers to the real life industrial working environment. It helps them in developing and enhancing their professional and personal competencies. The lecturers also benefit the industries by providing inputs and ideas about their products and service improvement. Further study need to be conducted to get the feedback from the industries and the view of the students regarding the performance of lecturers who undergone the program. The LIA programme could also be expanded abroad, especially among the OIC countries. This can expose the lecturers to the different working culture, languages and technology. The experience gained can be delivered to the students as a preparation and encouragement in exploring the opportunities abroad as to achieve organisational and global stability and security.

\section{References}

Imran, I. (2008). Presentation Status Report and Feedback on Issues Raised during Industry Dialogue 2008.

ILO/CINTERFOR. (2001). Labour Competencies. Regional Strategy for Technical and Vocational Education and Training. [Online] Available: http://www.cinterfor.org.uy/public/english/region/ampro/cinterfor/temas/comlab/doc/tvet/x.htm. (surfed 20 May 2008).

Mitchell, J., Henry, J. \& Young, S. (2001). Work based Learning in the Contemporary Australian VET Sector: A Reappraised. Reframing the Future Research Project. [Online] Available: http://www.avetra.or.au/abstracts_and_papers_2001/Henry-Mitchell-Young_full.pdf (surfed 20 May 2008). 